( $n=199$ patients), we validated the interaction between anti-CCP and RF with the clinical response to anti-TNF agents. ( $P=0.044)$.

Conclusion: The results of this study show that interactions between antibodies are important in the response to anti-TNF therapy and suggest potential pathogenic relationships.

Acknowledgments : We would like to thank the clinical researchers and patients participating in the IMID Consortium for their collaboration

Disclosure of Interests: Antonio Julià: None declared, Maria Lopez Lasanta: None declared, Francisco Blanco: None declared, Antonio Gómez: None declared, Isabel Haro: None declared, Antonio Juan Mas: None declared, Alba Erra: None declared, $\mathbf{M}^{\mathbf{a}}$ Luz García Vivar: None declared, Jordi Monfort: None declared, Simon Sánchez Fernandez: None declared, Isidoro González-Álvaro Grant/research support from: Roche Laboratories, Consultant of: Lilly, Sanofi, Paid instructor for: Lilly, Speakers bureau: Abbvie, MSD, Roche, Lilly, Mercedes Alperi-López: None declared, Raúl Castellanos: None declared, Antonio Fernandez-Nebro: None declared, Cesar Diaz Torne: None declared, Núria Palau: None declared, Raquel M Lastra: None declared, Jordi Lladós: None declared, Raimon Sanmarti: None declared, Sara Marsal: None declared DOI: 10.1136/annrheumdis-2020-eular.3801

\section{SAT0007 BLOCKING HISTAMINE-RELEASING FACTOR/ TRANSLATIONALLY CONTROLLED TUMOR PROTEIN (HRF/TCTP) ATTENUATES AGGRESSIVENESS OF FIBROBLAST-LIKE SYNOVIOCYTES AND AMELIORATES COLLAGEN-INDUCED ARTHRITIS IN RHEUMATOID ARTHRITIS}

M. Kim ${ }^{1}$, Y. Choe ${ }^{1}$, H. Lee ${ }^{1}$, Y. H. Cheon ${ }^{1}$, S. I. Lee ${ }^{1} .{ }^{1}$ Gyeongsang National University Hospital, Department of Internal Medicine, Jinju, Korea, Rep. of (South Korea)

Background: Histamine-releasing factor/translationally controlled tumor protein (HRF/TCTP) stimulates cancer progression and allergic responses. Increased expression of HRF/TCTP occurs in joints of rheumatoid arthritis (RA) patients, but the role of HRF/TCTP in RA remains undefined

Objectives: In this study, we explored the pathogenic significance of HRF/TCTP and evaluated therapeutic effects of HRF/TCTP blockade in RA.

Methods: HRF/TCTP transgenic (TG) and knockdown (KD) mice with collagen-induced arthritis ( $\mathrm{CIA})$ were used to determine experimental phenotypes of RA. HRF/TCTP levels were measured in sera and joint fluids in patients with RA and compared to those with osteoarthritis, ankylosing spondylitis, Behcet disease, and healthy controls. HRF/TCTP expression was also assessed in synovium and fibroblast-like synoviocytes (FLS) obtained from RA or OA patients. Finally, we assessed effects of HRF/TCTP and dimerized HRF/TCTP binding peptide-2 (dTBP2), an inhibitor of HRF/TCTP, in RA-FLS and CIA mice. Results: Our clinical, radiological, histological, and biochemical analyses indicate that inflammatory responses and joint destruction were increased in HRF/ TCTP TG mice, and decreased in KD mice compared to wild-type littermates. HRF/TCTP levels were higher in sera, synovial fluid, synovium, and FLS of patients with RA than in control groups. Serum levels of HRF/TCTP correlated well with disease activity in RA. Tumor-like aggressiveness of RA-FLS was exacerbated by HRF/TCTP stimulation and ameliorated by dTBP2 treatment. dTBP2 exerted protective and therapeutic effects in CIA mice, and had no detrimental effect in a murine tuberculosis model.

Conclusion: Our results indicate that HRF/TCTP represents a novel biomarker and therapeutic target for diagnosis and treatment of RA.

References: N/A

Acknowledgments : National Research Foundation of Korea

Korea Health Industry Development Institute

Disclosure of Interests: None declared

DOI: 10.1136/annrheumdis-2020-eular.5088

\section{SAT0008 INDIVIDUAL FUNCTIONS OF THE HISTONE- ACETYLTRANSFERASES CBP AND P300 IN REGULATING THE INFLAMMATORY RESPONSE BY AFFECTING HISTONE ACETYLATION AND MRNA STABILITY}

M. Krosel ${ }^{1,2}$, M. Gabathuler ${ }^{2}$, K. Walker ${ }^{2}$, M. Tomsic ${ }^{1}$, O. Distler ${ }^{2}$, C. Ospelt $^{2}$, K. Klein ${ }^{2} .{ }^{1}$ Department of Rheumatology, University Medical Centre Ljubljana, Ljubljana, Slovenia; ${ }^{2}$ Center of Experimental Rheumatology, Department of Rheumatology, University Hospital Zurich, Zurich, Switzerland

Background: Prolonged TNF-induced H3K27 acetylation (H3K27ac) and increased mRNA stability in rheumatoid arthritis (RA) synovial fibroblasts (SF) are leading to a sustained inflammatory response. Underlying enzymes coordinately regulating these pathways have not been identified so far. The histone acetyltransferases cAMP-response element binding protein binding protein
(CBP) and p300 are writers of activating H3K27ac marks and close homologues with widely accepted redundant functions.

Objectives: To analyze individual functions of CBP and p300 in regulating the inflammatory response of RA SF.

Methods: SF were isolated from patients with RA undergoing joint replacement surgery. The expression of CBP and p300 was silenced by transfection of antisense LNA gapmeRs $(12.5 \mathrm{nM})$. SF were stimulated with TNF $(10 \mathrm{ng} / \mathrm{ml})$ for $24 \mathrm{~h}$. Actinomycin D $(10 \mu \mathrm{g} / \mathrm{ml})$ was added $4 \mathrm{~h}$ after TNF-treatment for $2 \mathrm{~h}$ and $4 \mathrm{~h}(\mathrm{n}=3)$ to test mRNA stability. Transcriptomes were determined by RNA-seq (Illumina NovaSeq 6000, $n=6$ ). We mapped raw reads from RNA-seq reference genome using STAR. Counts for genes were obtained using Feature counts. We searched for differential expression genes (DEG) across experimental conditions using general linear models $(\mathrm{g} / \mathrm{m})$ implemented in 'edgeR' package of $\mathrm{R}$. Significantly affected genes $( \pm$ fold change $>1.5$, FDR $<0.05$, top 3000 genes included) entered pathway enrichment analysis for Gene Ontology (GO) biological process, and KEGG pathways in DAVID. Changes in the mRNA $(n=12-14)$ and protein expression $(n=6-12)$ were confirmed by quantitative Real-time PCR and ELISA. The levels of activating histone marks H3K27ac and nuclear localization of p50 and p65 were analyzed by Western blotting.

Results: DEG revealed that silencing of p300 affected the expression of 6026 and 5138 genes in unstimulated and stimulated SF, respectively. In contrast only 285 and 1911 genes were affected by CBP silencing in unstimulated and stimulated SF, respectively. In TNF-stimulated SF, pathway enrichment analysis of DEG revealed a key role of $\mathrm{CBP}$ in regulating the "type I interferon signaling pathway" $\left(p=2.12 \times 10^{-6}\right)$. Both, silencing of CBP and $p 300$ regulated genes enriched in the "TNF signaling pathway" (CBP: $p=0.005 ; p 300: p=0.031)$. In contrast to CBP silencing that had anti-inflammatory effects, silencing of p300 had pro-and anti-inflammatory effects. ELISA experiments suggested that silencing of CBP reduced the secretion of IL6 $(p<0.01)$, CCL2, CXC3L1 $(p<0.05)$, and CXCL12 $(p<0.001)$. Silencing of $p 300$ reduced the secretion of CCL2 $(p<0.001)$ and CXC3L1 $(p<0.05)$ but increased the expression of IL8 $(p<0.001)$ and CXCL2 $(p<0.05)$. Western blotting revealed that neither CBP, nor p300 silencing affected the nuclear expression of the NF-kB subunits $\mathrm{p} 65$ and $\mathrm{p} 50$. Silencing of p300 reduced the levels of H3K27ac by $30 \%$ in unstimulated SF, and by $61.4 \%(p<0.05)$ in presence of TNF. In addition to regulating H3K27ac, silencing of p300 regulated the expression of TNF-induced cytokines by increasing the mRNA stability of IL8, IL6 and CCL2 mRNA but not of CXCL2. Silencing of CBP reduced $\mathrm{H} 3 \mathrm{~K} 27 \mathrm{ac}$ by $43.5 \%$ only in presence of TNF and did not affect TNF-induced mRNA stability of cytokines. This is in line with the enrichment of the GO biological process "regulation of mRNA stability" $\left(p=2.61 \times 10^{-8}\right)$ being enriched only after silencing of p300.

Conclusion: Our results suggested that p300 is the major writer for H3K27ac marks in SF. Additionally, p300 regulated cytokine expression by affecting mRNA stability in a target-specific manner. We identified overlapping and distinct functions for CBP and p300 in regulating the inflammatory response of SF.

Disclosure of Interests: Monika Krosel: None declared, Marcel Gabathuler: None declared, Kellie Walker: None declared, Matija Tomsic: None declared, Oliver Distler Grant/research support from: Grants/Research support from Actelion, Bayer, Boehringer Ingelheim, Competitive Drug Development International Ltd. and Mitsubishi Tanabe; he also holds the issued Patent on mir-29 for the treatment of systemic sclerosis (US8247389, EP2331143)., Consultant of: Consultancy fees from Actelion, Acceleron Pharma, AnaMar, Bayer, Baecon Discovery, Blade Therapeutics, Boehringer, CSL Behring, Catenion, ChemomAb, Curzion Pharmaceuticals, Ergonex, Galapagos NV, GSK, Glenmark Pharmaceuticals Inventiva, Italfarmaco, iQvia, medac, Medscape, Mitsubishi Tanabe Pharma, MSD, Roche, Sanofi and UCB, Speakers bureau: Speaker fees from Actelion, Bayer, Boehringer Ingelheim, Medscape, Pfizer and Roche, Caroline Ospelt Consultant of: Consultancy fees from Gilead Sciences., Kerstin Klein: None declared

DOI: 10.1136/annrheumdis-2020-eular.3244

\section{SAT0009 \\ ROLE OF EC-18 IN AUTOIMMUNE ARTHRITIS AND INTERSTITIAL LUNG DISEASE IN CURDLAN- ADMINISTERED SKG MICE}

E. J. Lee ${ }^{1}$, D. H. Kim ${ }^{1}$, J. H. Lee ${ }^{1}$, S. J. Choi ${ }^{1}$, S. H. Nam ${ }^{1}$, J. S. Oh${ }^{2}$, E. J. Chang ${ }^{3}$, S. Hong ${ }^{1}$, C. K. Lee ${ }^{1}$, B. Yoo ${ }^{1}$, Y. G. Kim ${ }^{1} .{ }^{1}$ University of Ulsan College of Medicine, Asan Medical Center, Division of Rheumatology, Department of Medicine, Seoul, Korea, Rep. of (South Korea); ${ }^{2}$ Asan Medical Center, Department of Biomedical Informatics, Seoul, Korea, Rep. of (South Korea); ${ }^{3}$ University of Ulsan, Asan Medical Center, Department of Biomedical Science, College of Medicine, Seoul, Korea, Rep. of (South Korea)

Background: Although the mortality of patients with rheumatoid arthritis (RA) for which interstitial lung disease (ILD) is one of the major contributors, has still not decreased, new target therapies for RA have shown good response in peripheral arthritis. EC-18 (acetylated diacylglycerol 1-palmitoyl-2-linoleoyl-3acetyl-rac-glycerol) is a mono-acetyl-diglyceride that has been isolated from the 
antlers of sika deer and can be chemically synthesized from glycerol, palmitic acid, and linoleic acid. Research using LPS-induced acute lung injury murine model has reported that EC-18 stimulates a more rapid resolution of LPS-induced lung Inflammation. In addition, it has been reported that in a murine model of collagen-induced arthritis, EC-18 treatment ameliorated arthritis, with down-regulation of IL-6 level by regulating the activity of STAT3 in the synovium. Curdlan-administered SKG mice develop ILD spontaneously followed by peripheral arthritis, which resembles RA-ILD.

Objectives: We evaluated the modulatory effect of the EC-18 on arthritis and ILD in autoimmune arthritis animal model.

Methods: Male SKG mice were obtained from Dr. S. Sakaguchi. We injected curdlan (3mg/mice) in 8-week-old SKG mice and identified the presence of ILD by histological analysis at 20 weeks post-injection. Arthritis score was measured every week for up to 20 weeks. EC-18 $(250 \mathrm{mg} / \mathrm{kg}$ body weight/day, Enzychem Lifesciences Co., Daejeon, Korea) was administered every day orally. At 20 weeks post-injection, lung sections were stained with H\&E and Masson's trichrome. Using the Opal method, multiplexed immunofluorescent staining of lung tissue was performed. According to the scale by Ashcroft et al., fibrosis severity of lung sections was assessed by a system of eight grades. Analysis of serum cytokines by the luminex multiplex cytokine assay was performed at 20 weeks post-injection.

Results: Oral administration of EC-18 decreased arthritis score significantly until 8 weeks post-injection and remained unchanged thereafter. At 20 weeks post-injection, histological analysis showed severe pulmonary destruction, including bronchial alveolar tissue damage and massive leukocyte infiltration, and fibrosis in the curdlan-administered mice, which was attenuated in EC-18 treated mice. In particular, $67 \%$ of curdlan-administered mice showed ILD-like phenotype, whereas the incidence rate in EC-18-treated mice was $17 \%$. Furthermore, immunofluorescent-staining showed both IL-17A and neutrophil accumulation in lung in curdlan-administered mice; these were decreased in EC-18-treated mice. Interestingly, at 20weeks post-injection, EC-18 treatment down-regulated serum levels of IL-6 and TNF- $a$ and up-regulated sIL-7Ra (anti-fibrotic molecule).

Conclusion: Taken together, EC-18 exerts an anti-arthritic effect in early phase, but a long-term effect was not indicated. We emphasize the effect on ILD prevention of EC-18 via up-regulation of sIL-7Ra and inhibition of neutrophil accumulation, suggesting a therapeutic agent potentially for RA-ILD.

Disclosure of Interests: None declared

DOI: 10.1136/annrheumdis-2020-eular.4157

\section{SAT0010 ANTI-CD30 IMMUNOTHERAPY AMELIORATES BONE AND CARTILAGE DESTRUCTION IN EXPERIMENTAL MODEL OF RHEUMATOID ARTHRITIS IN MICE}

M. Matsuhashi ${ }^{1}$, K. Nishida ${ }^{1}$, Y. Nasu ${ }^{1}$, R. Nakahara ${ }^{1}$, M. Watanabe ${ }^{1}$, Y. Hotta ${ }^{1}$, T. Ozaki ${ }^{1} .{ }^{1}$ Department of Orthopaedic Surgery, Okayama University Graduate School of Medicine, Dentistry and Pharmaceutical Sciences, Okayama, Japan

Background: CD30 is a member of the TNF-receptor family and commonly expressed on lymphocytes of Hodgkin lymphoma and anaplastic large cell lymphoma. It has been reported that levels of soluble CD30 in serum and joint fluid is significantly elevated in rheumatoid arthritis (RA). Although RA patients may develop lymphoproliferative disorders (LPD) as a result of immunosuppression by MTX or bDMARDs, safety medications after the regression of LPD for RA have not yet been established.

Objectives: To explore the potential of CD30 targeting therapy for RA.

Methods: (1) Immuno-histological staining of CD30 was performed for fresh synovial tissues of RA and osteoarthritis (OA). In addition, double immunofluorescence staining of CD30 with CD3, CD20, CD68, CD138 were performed on RA synovial tissue. (2) Brentuximab vedotin (BV) is an anti-CD30 antibody conjugated with monomethyl auristatin $\mathrm{E}$, designed to induce apoptosis of CD30 expressing cells. A multiple myeloma cell line (RPMI8226) was used as a non-lymphoma cell line and plasma cell-like cell line. Immuno-cytological staining for CD30 was performed on RPMI8226. Cells were cultured and harvested on days 0,1 , and 3 to evaluate the effects of BV $(50 \mu \mathrm{l} / \mathrm{ml}$ per well). Cytospin specimens were stained by May-Grunwald-Giemsa (MGG) staining for cell counting and by FIFC-terminal deoxynucleotidyl transferase dUTP nick end labeling (TUNEL) staining for detection of apoptosis. (3) Collagen antibody induced arthritis (CAIA) was induced in DBA/1 mice by arthritogenic cocktail of monoclonal antibodies against type II collagen. BV was administered to the treatment groups (30 mg/kg and $70 \mathrm{mg} / \mathrm{kg} \mathrm{n}=4$ each) and evaluated clinical score, histological findings and levels of SAA, IL-6, and TNFa in serum by ELISA. Student's $t$-test (two-tailed) was used to determine statistical significance for analysis of synovial tissues and cell line assay. Two way ANOVA with Dunnett's post hoc analysis was used for multiple comparisons of mice model.

Results: (1) The number of CD30-positive cells was significantly higher in RA synovial tissue than in OA synovial tissue $(p<0.01)$ (Fig. 1). CD30-positive cells were detected around the lymphoid follicles. Double immunofluorescence showed CD30 and CD138 double-positive cells in the synovial tissue of RA, suggesting CD30 is predominantly expressed by plasma cells. (2) RPMI8226 cells expressed CD30. BV caused apoptosis of RPMI8226 cells, and the number of cells treated with BV decreased to $95 \%$ compared to controls. (3) All contro mice $(n=4)$ developed severe arthritis, and their scores reached a peak (score: 13.3) on day 10. In the mice of treatment group of $30 \mathrm{mg} / \mathrm{kg}$, paw swelling was slightly decreased, their clinical score reached a peak (score: 9.3) on day 10 In contrast, paw swelling was significantly reduced in the $70 \mathrm{mg} / \mathrm{kg}$ treatment group. The peak of the clinical score was 4.3 on day 10 (Fig.2). Histological score evaluated synovitis with infiltration of inflammatory cells, pannus formation, and erosion of bone and cartilage. Histological score of hind paws were $3.0 \pm 0.8$ for the control group, $2.7 \pm 1.0$ for $30 \mathrm{mg} / \mathrm{kg}$ group, and $0.7 \pm 1.1 \mathrm{for} 70 \mathrm{mg} / \mathrm{kg}$ group $(p<0.01)$, respectively. The serum levels of SAA and IL- 6 of treatment group were lower than those of no treatment group $(p<0.01)$.

Conclusion: We showed the expression of CD30 on synovial tissue of RA and the expression of CD30 on plasma cells. In addition, the current study provides the first evidence that BV depletion of CD30-positive cells suppressed arthritis and osteochondral destruction in CAIA mice. Our results may provide an important clue for the development of an effective treatment for RA with iatrogenic immunodeficiency-related LPD.

Fig. 1: Immuno-histological staining of $C D 30$ for fresh synovial tissues
RA

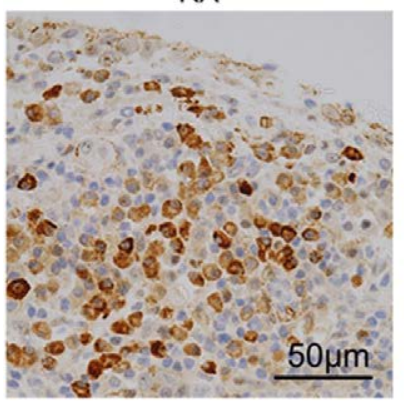

OA

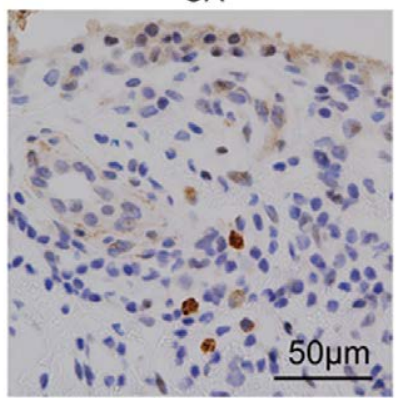

Fig. 2: BV dose-dependently suppress paw swelling and the clinical score of CAIA
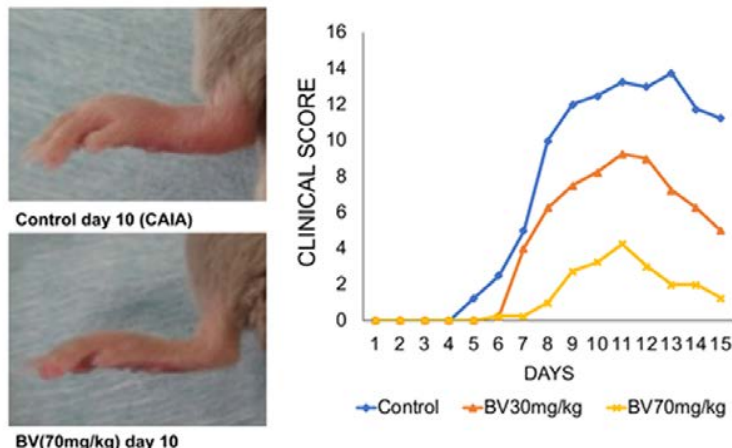

Disclosure of Interests: Minami Matsuhashi: None declared, Keiichiro Nishida Grant/research support from: K. Nishida has received scholarship donation from CHUGAI PHARMACEUTICAL Co., Eisai Co., Mitsubishi Tanabe Pharma and AbbVie GK., Speakers bureau: K. Nishida has received speaking fees from CHUGAI PHARMACEUTICAL Co., Eli Lilly, Janssen Pharmaceutical K.K., Eisa Co. and AYUMI Pharmaceutical Corporation., Yoshihisa Nasu: None declared Ryuichi Nakahara: None declared, Masahito Watanabe: None declared, Yoshifumi Hotta: None declared, Toshifumi Ozaki: None declared DOI: 10.1136/annrheumdis-2020-eular.1039

\section{SAT0011 COMBINED INHIBITION OF AUTOPHAGY AND GLUTAMINE METABOLISM SUPPRESSES CELL GROWTH OF RA SYNOVIOCYTES AND AMELIORATES ARTHRITIS IN SKG MICE}

I. Naka ${ }^{1}$, J. Saegusa ${ }^{1,2}$, K. Uto ${ }^{2}$, Y. Yamamoto ${ }^{1}$, Y. Ichise ${ }^{1}$, H. Yamada ${ }^{1}$ K. Akashi ${ }^{1}$, Y. Ueda ${ }^{1}$, A. Onishi ${ }^{1}$, T. Okano ${ }^{1,2}$, S. Takahashi ${ }^{1}$, S. Sendo ${ }^{1}$, A. Morinobu ${ }^{1} .{ }^{1}$ Rheumatology and Clinical Immunology, Kobe University Graduate School of Medicine, Kobe, Japan; ${ }^{2}$ Clinical Laboratory, Kobe University Hospital, Kobe, Japan

Background: Immunometabolism is now recognaized to be crucial in the pathogenesis of rheumatoid arthritis (RA). We have recently shown that the expression of glutaminase 1 (GLS1), a key enzyme in glutaminolysis, is upregulated in fibroblast-like synoviocytes from RA patients (RA-FLS) and that GLS1 inhibition 